\title{
Continuous two-step anaerobic digestion (TSAD) of organic market waste: rationalising process parameters
}

\author{
Carlos Enrique Gómez Camacho ${ }^{1} \cdot$ Bernardo Ruggeri $^{1}$ - Lorenzo Mangialardi ${ }^{1}$ Marco Persico ${ }^{1}$. \\ Andrea Cristina Luongo Malavé ${ }^{1}$
}

Received: 4 March 2019 / Accepted: 28 May 2019 / Published online: 4 July 2019

(c) The Author(s) 2019

\begin{abstract}
Experimental tests on continuous two-stage anaerobic digestion (TSAD) were conducted, to assess its energetic performance, using organic market waste as a substrate. The systems were tested to ascertain the effects of external stressors, which allow the separation into two different microorganism consortia, that is, hydrogen-producing bacteria and hydrogen-consuming bacteria, to be maintained. Two bioreactors were run in series under different operational conditions, including $\mathrm{pH}$, mixing rate, and initial inoculum, and three different decreasing hydraulic retention times were considered, with a fixed ratio of 1:10 in volume between the first bioreactor (hydrogen) and the second one (methane). The performance of the whole system was assessed over $>140$ days to monitor the stability of the process, in terms of the reduction of the volatile solids and the energy productivity for each step. Each tested condition was scored using two parameters: efficiency and efficacy. The first corresponds to the fraction of recovered energy of the available $(\eta)$ and the second $(\xi)$ was used to compare the energy produced by the TSAD with that of one-step anaerobic digestion. The efficiency resulted to be (24-32)\%, while the efficacy proved to be around 1.20. The share of energy, under the form of hydrogen, compared to the total energy recovery, was in the (8-12) \% range. Finally, the oscillation behaviour of the quasi-steady-state condition was analysed in terms of the Fano factor to establish the most stable conditions.
\end{abstract}

Keywords Microbiome $\cdot$ Two-stage mesophilic anaerobic digestion $\cdot$ Bio-hydrogen $\cdot$ Bio-methane $\cdot$ Hydraulic retention time $\cdot$ Selective pressure $\cdot$ Fano factor

\section{Introduction}

The feasibility of the use of mixed microbial consortia in anaerobic digestion (AD) for a wide range of organic substrates has been demonstrated during the last decades. In fact, $\mathrm{AD}$ is one of the most widespread energy-recovery processes throughout the world and it reached 16.6 Mtoe of primary energy production in Europe in 2016 [1], which represented $1.12 \%$ of the total EU primary energy consumption for that year. Moreover, different ongoing developments have also integrated $\mathrm{AD}$ in biorefinery context processes [2].

Currently, the most frequently used feedstock for AD is that of organic material, that is, either agro-industrial

Carlos Enrique Gómez Camacho

carlos.gomezcamacho@polito.it

1 DISAT, Department of Applied Science and Technology, Politecnico di Torino, C/so Duca degli Abruzzi 24, 10129 Turin, Italy production residues or the organic fraction of municipal solid waste (OFMSW), which is mainly constituted by cellulose, hemicellulose, and lignin. Bio-methane is produced using different inocula containing a wide variety of microorganisms, which progressively adapt to degrade the different organic constituents: carbohydrates, proteins, and lipids [3]. Large macromolecules are first hydrolysed to small-chain carbohydrates, while proteins are hydrolysed to amino acids and lipids to long-chain fatty acids. In acidogenesis, volatile fatty acids (VFA) are produced simultaneously with $\mathrm{H}_{2}$ and $\mathrm{CO}_{2}$ through dehydrogenation and decarboxylation reactions. Later, the acetogenic phase takes place converting the primary fermented products into acetic acid and $\mathrm{CO}_{2}$, which are used in methanogenesis by hydrogenotrophic methanogens $\left(\mathrm{CO}_{2}\right.$ and $\left.\mathrm{H}_{2}\right)$ and acetoclastic methanogens (acetic acid) together with other substances (methylated compounds), albeit to a lesser extent [4]. All the abovementioned phenomena are not independent; they are possible in $\mathrm{AD}$ microbiomes thanks to the fascinating syntrophic 
relationships that are established between fermenting bacteria and archaea. These bacteria produce surplus reducing power under the form of electrons, which is used by methanogens; these in turn need electrons, and this process is often referred to as interspecies electron transfer IET [5]. Moreover, several IET mechanisms, such as $\mathrm{H}_{2}$ and formate, have been proposed as shuttled and direct interspecies for electron exchange [6].

Microbial community engineering (MCE) is a growing topic of interest within the biotechnological field which comprehends species-species and species-environment interactions, including symbiotic associations (i.e., mutualistic, parasitic, or commensalistic), competition, and predation within species and strains. MCE has a high potentiality, which could be exploited for the production of chemicals [7], energy [8], and materials [9]. Species-species and species-environment interactions are related to the application of external stressors (selective pressure) to microbiomes, which are highly complex phenomena that can be studied using different approaches of a dynamic nature. The stability of a microbiome under environmental changes is, therefore, of the utmost importance.

Two-stage anaerobic digestion (TSAD) has recently been exploited using different microbiomes for each stage [10]. TSAD is conducted in one or two physically separated bioreactors: the latter in the case of continuous runs and the former for batch runs. The first step, i.e., bio- $\mathrm{H}_{2}$ production, is referred in the literature as Dark Fermentation (DF) and it has been studied extensively [11], while only a few studies are available on TSAD, and most of these are on the batch mode. TSAD permits more energy to be recovered than a one-stage process [12], not only due to the energy produced as hydrogen, but also because of the higher methane production. The reason for this enhancement is that the first stage serves as a biological pre-treatment, thus making the substrates more easily biodegradable by methanogens, and hence increasing the energy efficiency of the whole process $[13,14]$. As suggested in [10], the microbial consortia used to produce bio- $\mathrm{H}_{2}$ and bio- $\mathrm{CH}_{4}$ can be divided into two main groups, according to the pivotal role of $\mathrm{H}_{2}$ in $\mathrm{AD}$ : hydrogenproducing bacteria (HPB) and hydrogen-consuming bacteria (HCB). The first group is mainly composed of hydrolytic and fermentative microorganisms, and the second of fermentative microorganisms and methanogens.

In this context, continuous TSAD is a process that has been designed to separate the AD microbiomes into two bioreactors: ( $i$ ) a first one, aimed at producing $\mathrm{H}_{2}$ plus $\mathrm{CO}_{2}$ and a mixture of volatile fatty acids (VFA) that are present in the liquid phase, which is mainly carried out by HPB and (ii) a second one, which is fed with the liquid output stream from the first, and targets $\mathrm{CH}_{4}$ and $\mathrm{CO}_{2}$ production, and which contains a consortium of HCB and HPB. In the case of TSAD, it is mandatory to keep HPB separate from HCB in the first bioreactor. The separation can be obtained through the use of certain operational parameters (external stressors), such as: $\mathrm{pH}$, temperature, mixing rate, organic loading rate (OLR), Red-Ox potential, hydraulic retention time (HRT), concentration of inhibitory compounds, and kinetic selection of the microorganisms. The batch operation mode for TSAD systems was previously studied in [13]; however, it is necessary to pay more attention to the dynamics of the systems as far as the continuous mode is concerned, in particular to HRT [15] and OLR, which determine the growth kinetics of the microbial species, and hence indirectly the performance of the whole system.

The aim of this study was to experimentally evaluate the energetic performance and the stability of biogas production, using a quasi-pilot TSAD system operating in continuous mode, by selecting and maintaining the process parameters that are suitable for the microbiome present at each stage. Continuous operation was conducted using Organic Market Waste (OMW), taken from a local market, as the feed, under different HRT and OLR conditions. The performance of the TSAD system was evaluated by recording the amount of energy produced as $\mathrm{H}_{2}$ and $\mathrm{CH}_{4}$ in each step and the total recovered energy $\left(\mathrm{H}_{2}+\mathrm{CH}_{4}\right)$, compared to the energy obtained in one-stage AD using the efficiency and efficacy parameters. The stability analysis of quasi-steady-state condition was conducted over 120 days of continuous operation by evaluating the index of dispersion of fluctuations in gas productivity using Fano factors (FF).

\section{Materials and methods}

\section{Experimental set-up of the TSAD system}

The TSAD system consists of two CSTRs connected in series: a first bioreactor (S1), Minifors I (Infors HT, Bottmingen, Switzerland), with a total volume of $2 \mathrm{~L}$, which operates with a working volume of approximately $1.34 \mathrm{~L}$, and a second bioreactor (S2), Chemap Fermenter (Chemap AG. CH-8708, Manedorf, Switzerland), with a volume of $14 \mathrm{~L}$ and a fermentation volume of approximately $13.4 \mathrm{~L}$, i.e., with a reactor volume ratio (S1:S2) of 1:10. Both reactors operate under anaerobic conditions, which are reached by flushing $\mathrm{N}_{2}$ through the fermentation broth for $10 \mathrm{~min}$, and under mesophilic conditions at $35^{\circ} \mathrm{C}$, which is controlled by means of an electrical heater loop device. Different $\mathrm{pH}$ conditions have been applied to $\mathrm{S} 1$ and $\mathrm{S} 2$ to maintain different microbiomes in each reactor. In $\mathrm{S} 1$, the set point is $\mathrm{pH}_{\mathrm{S} 1}=5.5$, which was set to prevent solventogenesis at $\mathrm{pH}<5$ [16], while the set point in $\mathrm{S} 2$ is $\mathrm{pH}_{\mathrm{S} 2}=7$, chosen to prevent the lowering of methanogen activity at $\mathrm{pH}<6.5$ [10]. The $\mathrm{pH}$ values are controlled by means of 405-DPAS-SC-K8S/225 and 9816 Viscolyt sensors made 
(Mettler Toledo) for S1 and S2, respectively, and by means of two control loop devices, which act on peristaltic pumps using $2 \mathrm{~N} \mathrm{NaOH}$ solutions. In addition, mixing rates of 300 and $50 \mathrm{rpm}$ are applied in S1 and S2, respectively, and are maintained constant for the duration of the tests. A high mixing rate is necessary for $\mathrm{S} 1$ to degas the $\mathrm{H}_{2}$ dissolved in the liquid, which can potentially inhibit the bioreaction [6], and to prevent the formation of the aggregates between HPB and $\mathrm{HCB}$, which consume $\mathrm{H}_{2}$.

On the other hand, $\mathrm{S} 2$ requires a low mixing rate to favour the formation of the aggregates containing HPB and HCB and to prevent high hydrodynamic stress on the methanogens. The Red-Ox potential is measured in continuous mode by means of sensors inserted into S1 and S2 (Pt4805-DPASSC-K8S/225 and Pt4805-DPAS-SC-K8S, Mettler Toledo). Both bioreactors are operated in continuous mode with a slight overpressure ( $<50 \mathrm{mbar})$, which is maintained by means of two gas-over-flow valves, to avoid oxygen from infiltrating into the system. The complete system is only fed through the Minifors reactor, using a peristaltic pump with a feed frequency of $6 \mathrm{~h}$. The output stream from $\mathrm{S} 1$ reaches $\mathrm{S} 2$ by means of gravity-driven overflow, due to the difference in elevation between $\mathrm{S} 1$ and $\mathrm{S} 2$, which is about $50 \mathrm{~cm}$, as shown in the schematic representation of the experimental set-up (Fig. 1a) and in the picture in Fig. 1b.

Considering that $\mathrm{AD}$ is not only an energy-recovery technique, as is also satisfied the other environmental sustainability constraints, such as water consumption, the effluent of the process-the digestate-which is the output of the $\mathrm{CH}_{4}$ reactor and is not suitable for discharging into a receiving water body, has to undergo a separation step to recover the water (dewatering) and produce the dried digestate (about $40 \% w / w$ of humidity). The, thus, obtained water is then recycled and mixed with the fresh feed to avoid any
Fig. 1 a Scheme of the used pilot plant in continuous mode with $\mathrm{A}$ : the feed preparation tank; $\mathrm{B}$ : $\mathrm{BioH}_{2}$ reactor $(\mathrm{S} 1) \mathrm{C}$ : $\mathrm{BioCH}_{4}$ reactor (S2); D: absorption column; E: activated carbon adsorption column; F: heating system; G: Feed tank (one running, one in stand-by); $\mathrm{H}$ : crush screw; I: on line filter; L: control $\mathrm{pH}$ reservoirs; M: pressure control device; $\mathrm{N}$ : silica gel drying column; O: hydrogen gas rich storing tank under pressure; Q: biogas storing system at 1 atmosphere; R: digestate reservoir tank; S: liquid sampling device (from [10], published 2015 (C) Springer-Verlag London, reproduced with the kind permission of Springer Nature Customer Service Centre) and $\mathbf{b}$ pilot plant picture
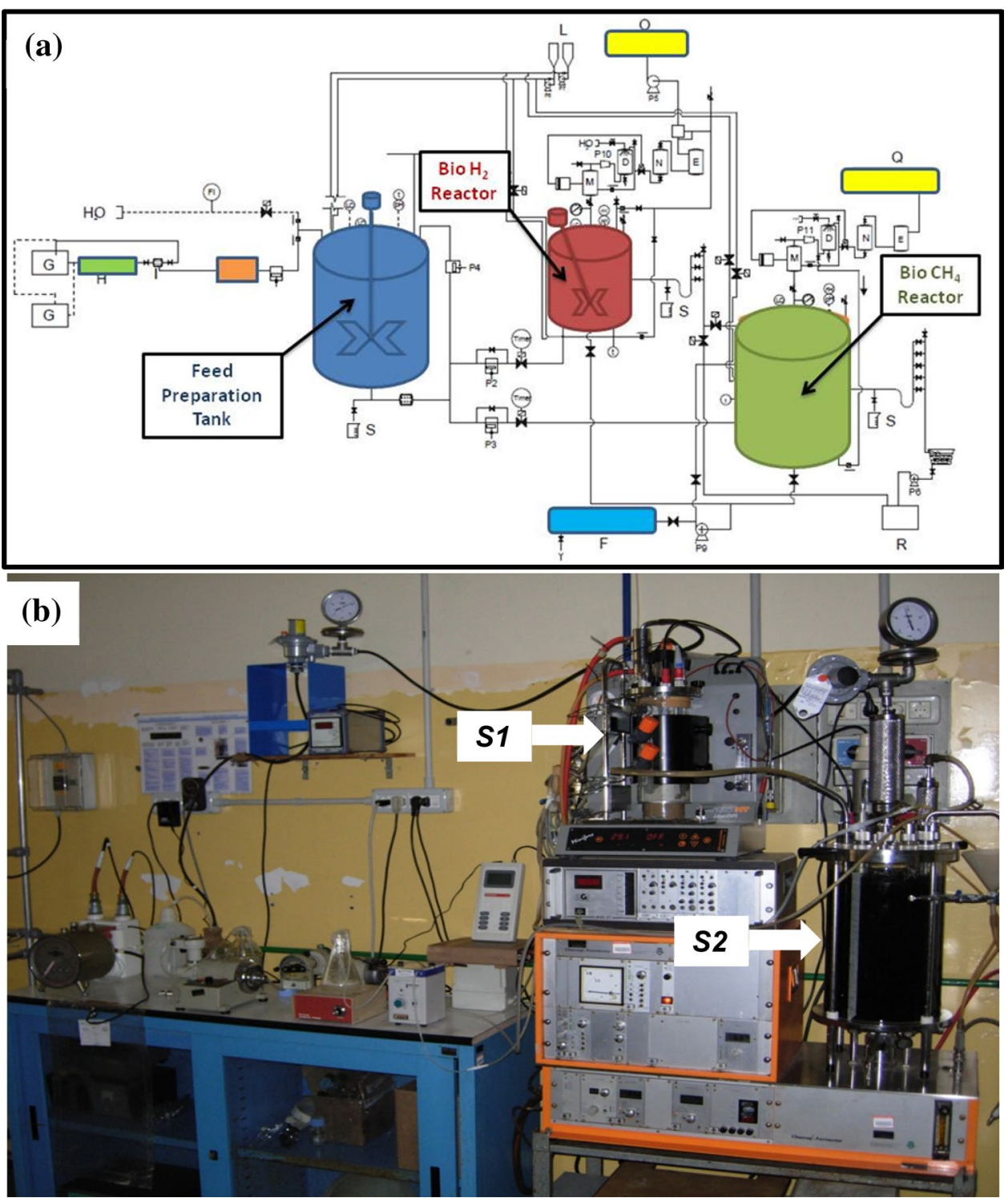
unnecessary water expenditure and to satisfy the water content requirements for the DF process for wet fermentation. However, in the case of TSAD, the water recycling stream also contains some HCB concentrations, which should not introduce any significant perturbations to the microbial composition in S1. In this respect, the output stream of S2 is filtered using $125 \mu \mathrm{m}$ nylon filters (Carl Roth $\mathrm{GmbH}$, Karlsruhe, Germany) and used to dilute the feed for S1.

\section{Preparation and pre-treatment of the substrate}

The selected substrate used for the tests was OMW, which was constituted by a random mixture of fruit and vegetables collected from an open market (the Racconigi Market, Turin, Italy). The OMW presented an elevated water content, of approximately $89-90 \% \mathrm{w} / \mathrm{w}$, which made it suitable for wet fermentation processes. Furthermore, the dry matter (DM) was mainly constituted by carbohydrates (sugars and fibres), of $70-90 \% \mathrm{w} / \mathrm{w}$, proteins of around $10-35 \% \mathrm{w} / \mathrm{w}$, lipids of $2-9 \% w / w$, and minerals of $3-5 \% \mathrm{w} / \mathrm{w}_{\mathrm{DM}}$. The collected refuses were ground and diluted with tap water for the first batch, without the addition of any substances, to obtain a homogenous solution which was then fed to the system. As a result of the long duration of the experimental campaign, different batches of substrate were prepared, following the procedure already reported in [17], but diluted with the filtered liquid discharged from methanogenic reactor S2 [18]. A representative composition of the feed to reactor $\mathrm{S} 1$ can be found in Table 1 .

\section{Preparation of the inocula}

The initial inocula used for both systems were cow manure. In the first stage (S1), the HPB inoculum was prepared by treating fresh manure at $\mathrm{pH}=3$ with a $2 \mathrm{M}$ solution of $\mathrm{HCl}$ at $35{ }^{\circ} \mathrm{C}$ for $24 \mathrm{~h}$ to reduce the population of methanogens (non-spore forming) following a procedure already reported in Ref. [19], to promote the enrichment of such spore-forming HPB as Clostridium spps. Fresh cow manure was used for the methanogenic reactor (S2), due to the suitability of its anaerobic microbial consortium. Both bioreactors were inoculated with a $10 \% v / v$ fraction of the working volume.

\section{Analytical measurements}

The proximate analysis consisted of the measurement of the dry matter (DM) and volatile solids (VS) according to the standard procedures [20]. The $\mathrm{pH}$ was measured using a $\mathrm{pH}$ metre (Laiss CONSORT P903, Turin, Italy). Cumulative gas production was assessed for each bioreactor using calibrated milligas counters (Ritter MGC-1 v3.2, Bochum, Germany). Both gas outputs were collected in plastic sampling bags (SKC Inc., Pennsylvania, USA) and analysed through offline gas chromatography, using a Micro-GC (Varian MicroGC CP-4900, Palo Alto, USA) equipped with a Thermal Conductivity Detector (TCD) and two columns: a poroplot $\mathrm{U}$ column for $\mathrm{CO}_{2}$ determination $\left(85^{\circ} \mathrm{C}, 200 \mathrm{kPa}\right.$ and Argon as the carrier) and a molecular sieve-type column for $\mathrm{H}_{2}, \mathrm{CH}_{4}$, $\mathrm{O}_{2}$, and $\mathrm{N}_{2}$ determination $\left(95^{\circ} \mathrm{C}, 200 \mathrm{kPa}\right.$, and helium as the carrier). The Lower Heating Values (LHV) of the substrates after dehydration at $105{ }^{\circ} \mathrm{C}$ for $24 \mathrm{~h}$ and pelletization of the DM were measured by means of a calorimetric bomb (ParrInstrument 1261, Moline, USA).

\section{Start-up of the TSAD system}

Bioreactors S1 and S2 were both inoculated with different consortia of microorganisms ("Preparation of the

Table 1 Model composition of the feed to S1

\begin{tabular}{lcccccccc}
\hline & $\%(\mathrm{w} / \mathrm{w})$ & Water $(\%)$ & Carbohydrates & Proteins & Lipids & Fibre & Other & Energy (kcal/g) \\
\hline Strawberry & 13.79 & 90.50 & 5.30 & 0.90 & 0.40 & 1.60 & 1.30 & 0.27 \\
Pear & 16.13 & 87.40 & 8.40 & 0.30 & 0.10 & 3.80 & 0.00 & 0.35 \\
Apple & 9.14 & 86.90 & 10.70 & 0.40 & 0.10 & 1.70 & 0.20 & 0.43 \\
Tomato & 22.98 & 93.16 & 3.53 & 0.88 & 0.22 & 1.99 & 0.22 & 0.19 \\
Zucchini & 6.33 & 93.60 & 1.40 & 1.30 & 0.10 & 1.20 & 2.40 & 0.11 \\
Peppers & 9.05 & 92.30 & 4.20 & 0.90 & 0.30 & 1.90 & 0.40 & 0.31 \\
Onion & 11.29 & 92.10 & 5.70 & 1.00 & 0.10 & 1.00 & 0.10 & 0.26 \\
Celery & 2.04 & 88.30 & 2.40 & 2.30 & 0.20 & 1.60 & 5.20 & 0.20 \\
Potato & 4.20 & 78.50 & 16.80 & 2.10 & 1.00 & 1.60 & 0.00 & 0.85 \\
Orange & 1.77 & 87.20 & 7.80 & 0.70 & 0.20 & 1.60 & 2.50 & 0.34 \\
Parsley & 1.41 & 87.20 & 1.00 & 3.70 & 0.60 & 5.00 & 2.50 & 0.20 \\
Lettuce & 1.87 & 94.30 & 2.20 & 1.80 & 0.40 & 1.30 & 0.00 & 0.19 \\
Mean \% & & 89.29 & 5.79 & 1.36 & 0.31 & 2.02 & 1.24 & 11.53 \\
Mean \% (dry basis) & & & 54.01 & 12.67 & 2.89 & 18.90 & \\
\hline
\end{tabular}


inocula") as seeds, since the generation of bio-hydrogen and bio-methane takes place in different microorganism populations (i.e., HPB and HCB). Considering that the necessary lag phase and duplication times are different in both cases, it was decided to first initiate the methanogenic bioreactor. Hence, the start-up procedure first involved the inoculation of S2 in batch mode, with the aim of establishing the microbial culture in the exponential-production phase of biogas $\left(\mathrm{CH}_{4}+\mathrm{CO}_{2}\right)$, which lasted about 30 days (Condition 0 , see Table 2). On the 15th day after the start-up of S2, the first stage (S1) was also inoculated to start in batch mode to let the microbial culture adapt to fermentative conditions. OWM, prepared as reported in "Preparation and pre-treatment of the substrate", was used in S1 and S2 under different operational parameters ("Experimental set-up of the TSAD system"). When S1 had approximately reached the time corresponding to the exponential phase independently, the two bioreactors were connected by opening the connection liquid valve (Fig. 1), and the continuous operation of the twostage (TSAD) system was launched (see Fig. 2 for the experimental design sequence). After the system had been run for a time approximately equal to that of the longer HRT (15 days), in continuous mode, corresponding to 1 cycle of HRT for S2 and 10 cycles of HRT for S1, tests were carried out on the system in quasi-steady-state conditions, starting with the higher HRT tested of 15 days. Due to the type of nutrients-rich substrate ("Preparation and pre-treatment of the substrate") selected for the tests, the start-up of the anaerobic fermentations in batch mode is rather simple; however, the energy-recovery stability of the TSAD is to be tested in the continuous-mode operation, for which different HRT conditions were scanned.

\section{Screening of the different hydraulic retention times (HRT)}

Once the batch operation of S1 and S2 reached the exponential phase, and the operation switched to the continuous mode, three operative HRT conditions, namely I, II, and III, which are reported in Table 2, were tested. To observe the oscillation of bio- $\mathrm{H}_{2}$ and bio- $\mathrm{CH}_{4}$ production, it was decided to use as a probe parameter different conditions of HRT for each stage. Considering that the volume of the broth in S2 was ten times that in $\mathrm{S} 1$, and that the total liquid discharged from $\mathrm{S} 1$ was fed to $\mathrm{S} 2$, the $\mathrm{HRT}_{\mathrm{S} 1}$ : $\mathrm{HRT}_{\mathrm{S} 2}$ ratio was also fixed at 1:10. HPB and HCB are constituted by ecologically different microorganisms with different specific growth rates $\left(\mu_{\max }\right)$, that is, of approximately 0.215 and $0.010 \mathrm{~h}^{-1}$, respectively [10]; and since the operation was conducted in CSTR reactors, each HRT-tested condition was applied for three cycles of S2 to encompass the variability of $\mu_{\max }$ of the different species present in the consortia. Hence, the evaluation of the performance lasted 30 cycles of each HRT for S1 (see Table 2), which can be considered not only sufficiently long time to separate HPB from HCB, but also an adequate time window to observe the passage from one pseudo-steady-state into the next condition, using 3 and 30 cycles, for $\mathrm{S} 1$ and $\mathrm{S} 2$, respectively. The first set of tested HRT corresponds to 1.5 and 15 days for $\mathrm{S} 1$ and $\mathrm{S} 2$, respectively; these are the longest retention times (the lowest feeding rates) and they were progressively decreased.

\section{Kinetic selection of the microorganisms based on HRT}

To assure the long-term stability of HPB and HCB populations, not only were such process parameters as the $\mathrm{pH}$ and the mixing rate kept different in $\mathrm{S} 1$ and $\mathrm{S} 2$, but the so-called kinetic selection was also tested, due to its fundamental role

Table 2 Tested HRT conditions for the TSAD system

\begin{tabular}{lllllll}
\hline Condition & Mode & $\begin{array}{l}\text { Testing } \\
\text { period } \\
\text { (day) }\end{array}$ & HRT S1 (day) & Cycles S1 (-) & HRT S2 (day) & Cycles S2 (-) \\
\hline 0 (start-up) & Batch & 30 & - & - & - & - \\
I & Continuous & 45 & 1.5 & 30 & 15 & 3 \\
II & Continuous & 36 & 1.2 & 30 & 12 & 3 \\
III & Continuous & 33 & 1.1 & 30 & 11 & 3 \\
\hline
\end{tabular}

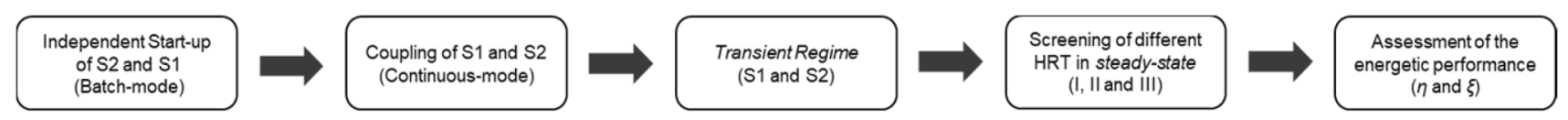

Fig. 2 Block diagram of the experimental procedure 
in continuous plant operation [21]. This involves the application of the wash-out criterium of a chemostat containing different microorganism species, each with its own specific growth rate. The growth rates $(\mu)$ are inversely related to the doubling times of the microorganisms, e.g., $t_{\mathrm{d}}=\ln (2) / \mu_{\max }$, which is a more intuitive parameter. As previously mentioned, HPB presents shorter doubling times than HCB and, hence, a greater $\mu_{\max }$, while HCB has a longer $t_{\mathrm{d}}$, and, therefore, requires a longer HRT to reproduce. The large temporal differences necessary for HCB and HPB to reproduce promote a kinetic selection of different microbiomes. It is possible to understand this selection if we consider, for simplicity, an ideal continuous stirred tank reactor (CSTR) containing only one bacteria species $(X)$ and only one organic substrate $(S)$. Considering that bacterial growth follows Monod kinetics, in a steady-state (ss) condition, the constitutive mass balance equations become:

$S_{\mathrm{SS}}=\frac{K_{\mathrm{S}} \times D}{\left(\mu_{\max }-D\right)}$

$X_{\mathrm{SS}}=Y_{X / S} \times\left(S_{0}-S_{\mathrm{SS}}\right)$

where $\mu_{\max }$ is the maximum specific growth rate of the microorganism $\left(\mathrm{h}^{-1}\right), D$ is the dilution rate $D=Q / V=\mathrm{HRT}^{-1}$ $\left(\mathrm{h}^{-1}\right), Q$ is the flow rate $(\mathrm{L} / \mathrm{h}), V$ is the volume $(\mathrm{L}), K_{s}$ is the affinity constant $\left(\mathrm{g}_{\mathrm{S}} / \mathrm{L}\right), Y_{X / S}\left(\mathrm{~g}_{\mathrm{X}} / \mathrm{g}_{\mathrm{S}}\right)$ is the yield coefficient of the biomass, and $S_{0}\left(\mathrm{~g}_{\mathrm{S}} / \mathrm{L}\right)$ is the substrate concentration in the feed stream. From Eqs. (1) and (2), as $D$ approaches $\mu_{\max }, S_{\mathrm{ss}}$ approaches $S_{0}$, and hence, $X_{\mathrm{ss}}$ approaches zero. This condition means that the chemostat bioreactor goes into wash-out $\left(X_{\mathrm{SS}} \rightarrow 0\right)$ : no microorganisms are now present in the bioreactor and the bioreaction stops. Since HRT $=D^{-1}$, in the case of a bioreactor containing two species of microorganisms, working with a shorter HRT than doubling time $t_{\mathrm{d}}$ of one species will promote the wash-out of the second one.

In the present case, the two populations of interest (HPB and $\mathrm{HCB}$ ) are constituted by hundreds of species, each with a particular value of $t_{\mathrm{d}}$, and experimental reference values should, therefore, be considered to represent all the involved species. Figure 3 shows, in a qualitative way, the application of kinetic selection to TSAD system, where the nominal trends for the substrate concentrations $(S)$ and biomass $(X)$ are presented under steady-state conditions. The dashed vertical lines represent the wash-out of each species, while the vertical bands represent possible operative ranges of HRT for S1 and S2. As can be observed in Fig. 3, an adequate separation of HPB and HCB occurs: only HPB species are present in S1, while a balance between HPB and HCB in S2 allows syntrophy to be reached between the microbial populations of interest. The substrate concentration decreases as is passes through the cascade of bioreactors: $S_{0}$ is the feed substrate concentration for $\mathrm{S} 1, S_{1}$ is the outlet concentration of $\mathrm{S} 1$ and is also the inlet concentration for $\mathrm{S} 2$, and, finally, $S_{2}$ is the concentration of the second stage (S2).

\section{Efficiency ( $\eta$ ) and efficacy (ל) evaluations}

The energetic performance of the continuous TSAD system was evaluated using two parameters: $(i)$ efficiency $(\eta)$, which considers the produced energy as the sum of the obtained $\mathrm{H}_{2}+\mathrm{CH}_{4}$, compared to the amount of energy present in the OMW fed to the system, through its LHV $\left(\mathrm{kJ} / \mathrm{g}_{\mathrm{DM}}\right)$; (ii) efficacy $(\zeta)$, which takes into consideration the energy produced with the TSAD system, compared with the energy produced under an exclusively methane form in the one-stage $\mathrm{AD}$ for the same substrate. The concepts of this approach have been
Fig. 3 Graphical representation of Eqs. 1 and 2, evidencing the kinetic selection of microorganisms based on HRT

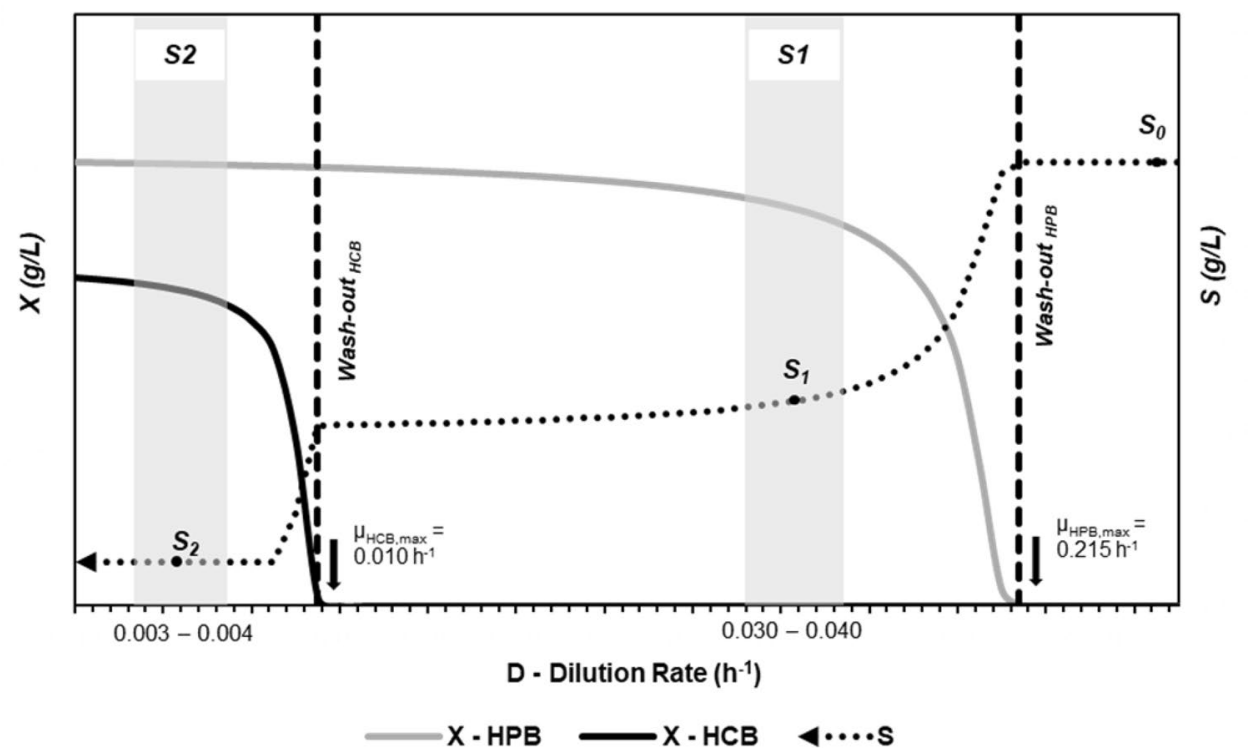


previously introduced in Ref. [13], and it is here sufficient to highlight the lower experimental uncertainty linked to the determination of LHV, which is valid for any type of organic refuse. This approach is preferred to the use of biological methane potential (BMP), since the energy in TSAD is produced under the form of $\mathrm{H}_{2}+\mathrm{CH}_{4}$, and mainly because the former step modifies the efficiency of the methanogenic step [12].

The efficiency was evaluated as follows:

$\eta=\frac{\frac{\dot{\varphi}_{\mathrm{S} 1}}{22.41} \times y_{\mathrm{S} 1, \mathrm{H}_{2}} \times \mathrm{LHV}_{\mathrm{H}_{2}}+\frac{\dot{\nu}_{\mathrm{S} 2}}{22.41} \times y_{\mathrm{S}_{2}, \mathrm{CH}_{4}} \times \mathrm{LHV}_{\mathrm{CH}_{4}}}{Q_{\mathrm{S} 1} \times \mathrm{VS}_{\mathrm{OMW}} \times \mathrm{LHV}_{\mathrm{OMW}}}$,

where $v_{\mathrm{S} 1}$ and $v_{\mathrm{S} 2}$ are the experimentally measured (NL/h) mean biogas flow rates from S1 and $\mathrm{S} 2 ; y_{\mathrm{S} 1, \mathrm{H}_{2}}$ and $y_{\mathrm{S} 2, \mathrm{CH}_{4}}$ are the gas mole fractions $(\mathrm{mol} / \mathrm{mol})$ of the gas for each stage (i.e., $\mathrm{H}_{2}$ in $\mathrm{S} 1$ and $\mathrm{CH}_{4}$ in $\mathrm{S} 2$ ), $\mathrm{LHV}_{\mathrm{H}_{2}}$ and $\mathrm{LHV}_{\mathrm{CH}_{4}}$ are the molar LHVs of hydrogen and methane, respectively $(239.2 \mathrm{~kJ} / \mathrm{mol}$ and $800.29 \mathrm{~kJ} / \mathrm{mol}) ; 22.41 \mathrm{NL} / \mathrm{mol}$ is the volume occupied by $1 \mathrm{~mol}$ of ideal gas; $Q_{\mathrm{S} 1}$ corresponds to the mean feeding flow rate $(\mathrm{L} / \mathrm{h})$ for each tested HRT condition of $\mathrm{S} 1, \mathrm{VS}_{\mathrm{OMW}}$ is the mean concentration of the volatile matter $\left(\mathrm{g}_{\mathrm{VS}} / \mathrm{L}\right)$ present in the OMW and $\mathrm{LHV}_{\mathrm{OMW}}=(14.538 \pm 150) \mathrm{kJ} / \mathrm{g}_{\mathrm{VS}}$, as experimentally determined. The efficacy of TSAD was calculated as follows:

$\zeta=\frac{\mathrm{Ep}_{\mathrm{TSAD}}}{\mathrm{Ep}_{\mathrm{AD}}}$

where $\mathrm{Ep}_{\mathrm{TSAD}}$ is the energy produced by the TSAD systems (i.e., the numerator of Eq. 3) and $\mathrm{Ep}_{\mathrm{AD}}$ (Eq. 5) is the energy produced by the same feed in the one-stage $\mathrm{AD}$. In the present case, $\mathrm{Ep}_{\mathrm{AD}}$ was experimentally evaluated in batch mode (test not shown) and a mean value of $0.151 \mathrm{~L}_{\mathrm{CH} 4} / \mathrm{g}_{\mathrm{VS}}$ was obtained, and hence:

$\mathrm{EpAD}=\frac{0.151}{22.41} \times \mathrm{LHV}_{\mathrm{CH}_{4}} \times Q_{\mathrm{VS}} \quad(\mathrm{kJ} /$ day $)$

permits the energy produced in the one-step AD to be evaluated as a reference value for each tested HRT, where $Q_{\mathrm{VS}}$ $\left(\mathrm{g}_{\mathrm{vS}} / \mathrm{h}\right)$ is the feed for each condition.

\section{Results and discussion}

\section{Volatile solid (VS) concentrations along the TSAD system}

During the continuous test, the operative conditions were kept constant, as mentioned in "Experimental set-up of the TSAD system". The fed substrate had variable characteristics, since it was prepared periodically (i.e., every Monday) from refuses to simulate full-scale conditions, and it was used during the following week. Figure 4 shows the monitored concentration of VS for the three tested HRT in the feed, as well as the output from S1 and the digestate (output from S2) to help understand the behaviour of the TSAD system. It is important to note that the time axis considered and reported in the figures only regards the time of operation in pseudo-steady-state, and, hence, 3 HRT for S2 and 30 HRT for S1. The mean VS concentrations in the feeds for each condition (I, II, and III) were 29.2 $\pm 8.5,32.1 \pm 3.8$, and $29.1 \pm 1.6 \mathrm{~g}_{\mathrm{VS}} / \mathrm{L}$, for each case (Fig. 4). To simulate the behaviour of the full plant, due to the variations of the feed characteristics as a consequence of the periodical collection of the refuses, the feeds were only treated as reported in "Preparation and pre-treatment of the substrate", this explains the constant OLR for only certain lapses. It is evident that the system can absorb the very large variations of OLR for all the cases. In case I, that is, the system with the longest HRT, the variability in the feed was greater, and hence, higher oscillations were observed, and for some days, the difference between the input and output of S2 was very narrow. It should be noted that even when the VS concentration had more variability, the mean OLR showed a variability of between 10 and $25 \%$ (see Table 3), which is the same range as that of full-scale digesters, and was always within ranges commonly found in the literature for wet fermentation conditions [22]. The response of S2 was also smoother for the three tested conditions, a result that could be related to the lower activity of the HCB consortia and the longer HRT (see " $\mathrm{H}_{2}$ and $\mathrm{CH}_{4}$ production in $\mathrm{S} 1$ and $\mathrm{S} 2$ for different HRT”).

\section{$\mathrm{H}_{2}$ and $\mathrm{CH}_{4}$ production in $\mathrm{S} 1$ and $\mathrm{S} 2$ for different HRT}

As previously mentioned, the produced energy was evaluated considering the energy produced under the form of $\mathrm{H}_{2}$ and $\mathrm{CH}_{4}$. To this end, the specific daily productivity $\mathrm{NL}_{\mathrm{gas}}$ ' $\left(\mathrm{L}_{\text {broth }}\right.$ day) was recorded for each stage (S1 and $\mathrm{S} 2$ ) for the tested conditions of HRTs (I, II, III). The trends are presented in Fig. 5, where the duration of the tests (three cycles of each HRT condition for S2 and 30 cycles per HRT for S1) is reported on the time axis. Oscillatory behaviour can be observed for both reactors. The observed oscillations in the case of $\mathrm{H}_{2}$ productivity are larger than $\mathrm{CH}_{4}$, probably due to the larger feed variations, and are remarkably unstable under the three tested HRT. On the other hand, the $\mathrm{CH}_{4}$ productivity presents a lower amplitude than $\mathrm{H}_{2}$, but the oscillations are quite smooth, and the productivity appears almost constant at HRT $=15$ days. The oscillation could be related to many different aspects, such as the dynamics of synergic interactions of the microorganisms and reactor phenomena. Since the consortia in S1 and S2 required different adaptation times, the specific growth rate of the microbiome depends on the microorganism's synergies, 
Fig. 4 Behaviour of the volatile solid concentrations under different HRT: a I, b II, and c III
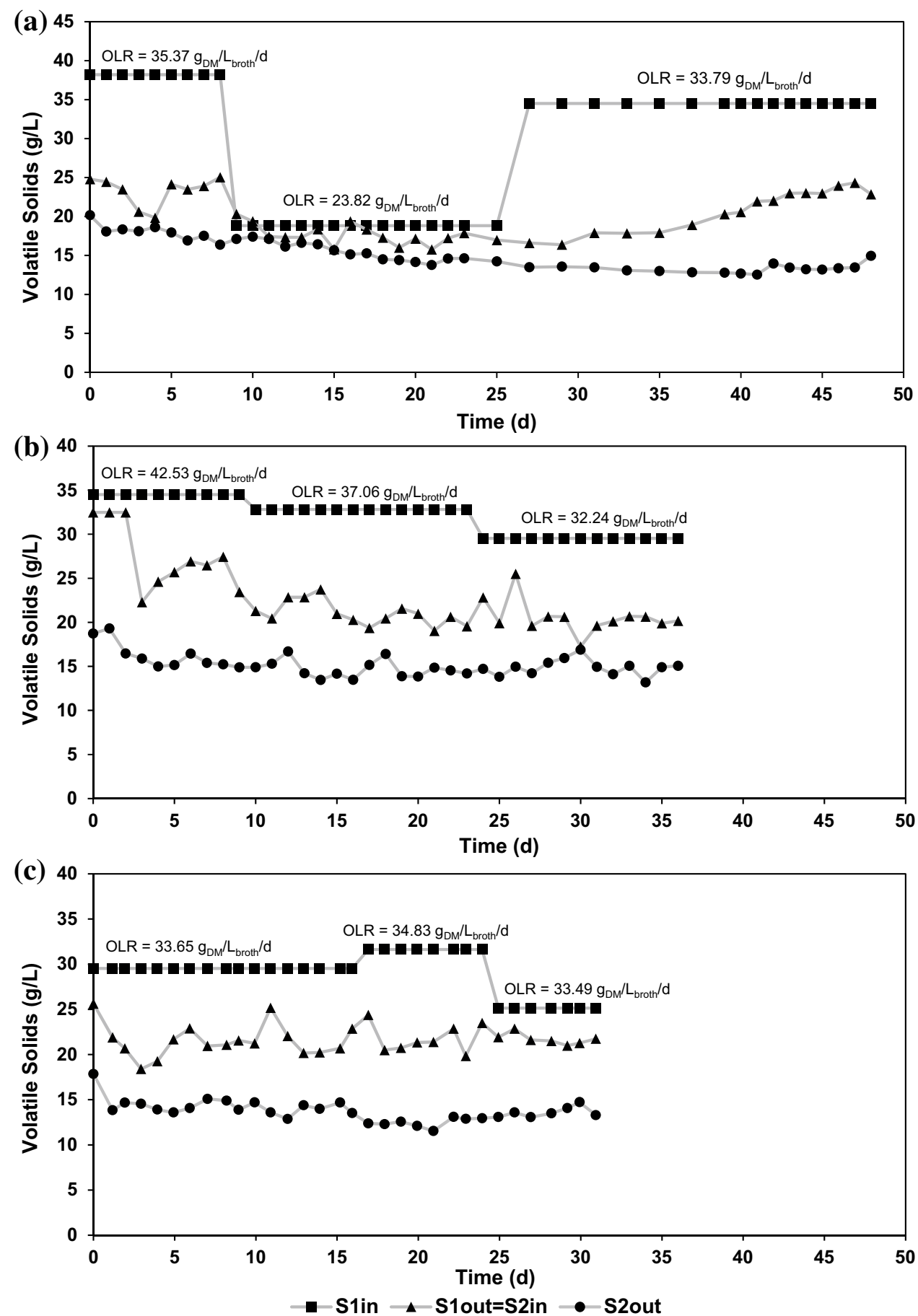

while other relevant reactor phenomena, such as the residence time, the circulation, and mixing times in the vessel as well as the local viscosity and its temporal variations, could affect too the magnitude of oscillation in both bioreactors. As the experimental procedure evolved from I $\rightarrow \mathrm{II} \rightarrow \mathrm{III}$, the HRT is decreased, therefore, the overall adaptation of the system should move towards case III. The mean $\mathrm{H}_{2}$ productivity amounted to $(1.437 \pm 0.431),(1.429 \pm 0.291)$ and $(1.219 \pm 0.152) \mathrm{L}_{\mathrm{H}_{2}} /\left(\mathrm{L}_{\text {broth }}\right.$ day $)$, while, for $\mathrm{CH}_{4}$, it amounted to $(0.299 \pm 0.030),(0.320 \pm 0.019)$, and $(0.471 \pm 0.088)$ $\mathrm{L}_{\mathrm{CH}_{4}} /\left(\mathrm{L}_{\text {broth }}\right.$ day) for I, II, and III HRTs, respectively. The relative variability for $\mathrm{H}_{2}$ productivity lay around $12-30 \%$, while, for the case of $\mathrm{CH}_{4}$, it was about 6-18\%, values which are within the previously reported range of experimental data [14].

Since quite complex higher order phenomena, such as those recalled above, could affect the oscillations in both S1 and S2, which are always observed in the case of 
Table 3 Performance results and operative conditions for each tested condition I, II, and III

Fig. 5 Specific $\mathrm{H}_{2}$ and $\mathrm{CH}_{4}$ productivity for the different tested HRT

\begin{tabular}{llll}
\hline & $\mathrm{I}$ & $\mathrm{II}$ & $\mathrm{III}$ \\
\hline $\mathrm{S} 1-\mathrm{HRT}($ day) & 1.5 & 1.2 & 1.1 \\
$\mathrm{~S} 2-\mathrm{HRT}($ day) & 15 & 12 & 11 \\
$\mathrm{~S} 1$-feed (L/day) & $0.89 \pm 0.05$ & $1.12 \pm 0.05$ & $1.21 \pm 0.05$ \\
$\mathrm{~S} 1-\mathrm{OLR}\left[\mathrm{g}_{\mathrm{VS}} /(\mathrm{L}\right.$ day)] & $19.39 \pm 5.65$ & $26.84 \pm 1.71$ & $19.54 \pm 2.00$ \\
$\mathrm{~S} 2-\mathrm{OLR}\left[\mathrm{g}_{\mathrm{VS}} /(\mathrm{L}\right.$ day $\left.)\right]$ & $1.33 \pm 0.19$ & $1.27 \pm 0.11$ & $1.95 \pm 0.14$ \\
$\mathrm{~S} 1-\mathrm{H}_{2}$ productivity $\left[\mathrm{NL}_{\mathrm{H}_{2}} /\left(\mathrm{L}_{\text {broth }}\right.\right.$ day $\left.)\right]$ & $1.437 \pm 0.431$ & $1.428 \pm 0.291$ & $1.219 \pm 0.152$ \\
$\mathrm{~S} 2-\mathrm{CH}_{4}$ Productivity $\left[\mathrm{NL}_{\mathrm{CH}_{4}} /\left(\mathrm{L}_{\text {broth }}\right.\right.$ day $\left.)\right]$ & $0.299 \pm 0.030$ & $0.320 \pm 0.019$ & $0.471 \pm 0.088$ \\
$\mathrm{~S} 1-\mathrm{H}_{2}$ yield $\left(\mathrm{NL}_{\mathrm{H}_{2}} / \mathrm{g}_{\mathrm{VS}}\right)$ & $0.074 \pm 0.029$ & $0.053 \pm 0.011$ & $0.050 \pm 0.006$ \\
$\mathrm{~S} 2-\mathrm{CH}_{4}$ yield $\left(\mathrm{NL}_{\mathrm{CH}} / \mathrm{g}_{\mathrm{VS}}\right)$ & $0.154 \pm 0.055$ & $0.119 \pm 0.007$ & $0.179 \pm 0.033$ \\
$\mathrm{Mean}$ daily produced energy $(\mathrm{kJ} /$ day) & $163.89 \pm 14.50$ & $173.79 \pm 1.30$ & $243.15 \pm 4.44$ \\
Mean daily available energy $(\mathrm{kJ} /$ day) & $579.75 \pm 145.42$ & $717.73 \pm 41.45$ & $750.78 \pm 80.45$ \\
Efficiency $(\eta)$ & $0.28 \pm 0.08$ & $0.24 \pm 0.01$ & $0.32 \pm 0.04$ \\
Efficacy $(\xi)$ & $1.18 \pm 0.34$ & $0.90 \pm 0.04$ & $1.29 \pm 0.16$ \\
\hline
\end{tabular}

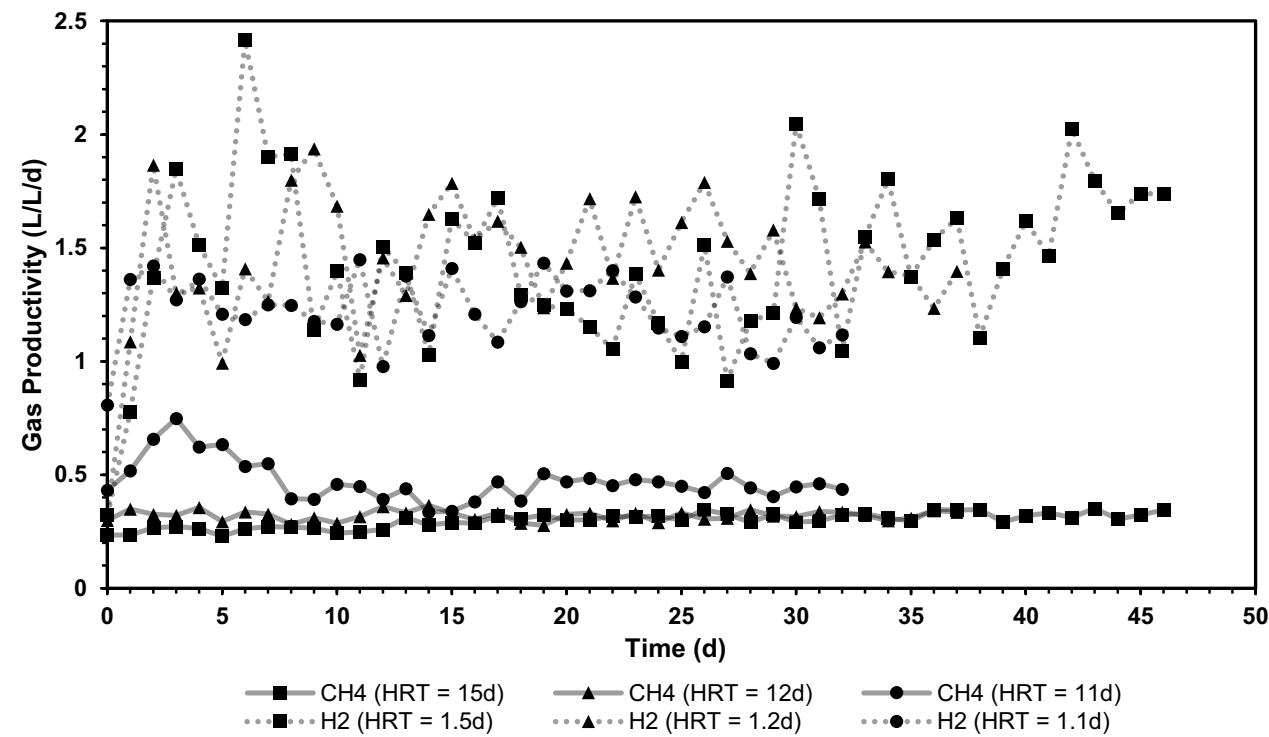

full-plant scale AD, it is very difficult to provide an explanation for each case. However, it is possible to hypothesise that, in conditions where the system is operated for shorter HRT, these variations are likely to be more related to macroscopic operating conditions, such as: fluctuating OLR, differences between HRT and the microorganism retention time, non-ideal mixing conditions, and the amplitude of the spatial gradients in the vessel. On the other hand, when the feed is replaced less frequently at longer HRT, the system could be dominated by microbiological behaviour, such as competition, selection among the microorganisms, and metabolic shifts between different species present in both bioreactors. However, the role of the $\mathrm{S} 1$ as a pretreatment step that is able to absorb; to some extent, the perturbations of the feed entering methanogenic bioreactor S2 can be observed from Fig. 5. Given the difficulties to explain in detail the mechanisms that generate the oscillations, a macro-analysis is presented in the following section.

\section{Statistical analysis of the TSAD in a pseudo-steady-state condition}

A statistical analysis was conducted to analyse the oscillatory behaviour reported in Fig. 5 for the continuous operation, even though the size of the sampling data is limited (i.e., about 30-50 points for each tested condition). Conducting a stochastic analysis in the present context means studying the properties of random time series or, more precisely, of complex erratic phenomena. This includes the study of the mean, variance, and correlation functions, as traditional measures of the properties of random data. When the time series are such that the variance and/or the mean diverge over the observation parameters, as occurs for the 
productivities reported in Fig. 5, it is necessary to analyse the heterogeneity properties of measurement by determining how the variance depends on the size of the units used to measure the time series. In other words, attention needs to be oriented towards the assessment of the temporal heterogeneity of the phenomena. A parameter that is able to give information on the intermittent increases and decreases in an activity or the frequency of an event is called burstiness. One of the measures of burstiness is: $\mathrm{FF}=\sigma^{2} / M$ over a specified time scale, i.e., the ratio of the variance of the events over the mean value of the events that occur over a certain counting time, which is called the Fano factor (FF). It is also called the index of dispersion and was introduced by the Italian mathematician Ugo Fano in 1947 [23] to analyse the number of ions produced in a volume of gas by the absorption of such radiation. The FF has recently gained popularity in a variety of applications in different fields [24], including genetics [25] and biochemical enzyme pathway predictions [26]. As far as physical significance is concerned, it is possible to argue that the lower the FF is, the more the system obeys a deterministic law, i.e., when the noise disturbance is low, the higher the FF, and the more the system is of a statistical nature, the greater the noise effects. In the present case, $\mathrm{FF}$ was evaluated by computing the $\sigma^{2}$ of the spikes of

Table 4 Fano factor evaluation considering the total data for each HRT

\begin{tabular}{llll}
\hline $\mathrm{FF} \times 10^{2}$ & HRT I & HRT II & HRT III \\
\hline $\mathrm{S} 1$ & 9.8541 & 6.0562 & 1.8761 \\
$\mathrm{~S} 2$ & 0.3625 & 0.1551 & 1.7216 \\
\hline
\end{tabular}

productivity and the mean value $(M)$ of the data reported in Fig. 5. FF was evaluated for two situations: (i) for the entire duration of the testing period in pseudo-state-state for each HRT, which is reported in Table 4 and (ii) for a time interval of observation equal to one cycle of HRT for S2, for each tested HRT condition, for both S1 and S2, shown in Fig. 6 .

As a first consideration, it is possible to see, from Table 4, that the FF for $\mathrm{S} 2$ for all the tested HRT is much lower than that of $\mathrm{S} 1$, meaning that methane bioreactor $\mathrm{S} 2$ is stabilised by $\mathrm{S} 1$, as a result of the lowering of the disturbance, due to the variations of the above-quoted operative variables. A second consideration regards the selection of the operative HRT. As is possible to see from Table 4, as the HRT decreases from I to II and III, the stability of S1 increases, as can be seen from the decreases in FF. This means that the bio-hydrogen bioreactor could be operated even at HRT $<1.1$ days. Instead, for $\mathrm{S} 2$, the stability increases from I to II and decreases from II to III; in fact, the FF decreases from I to II, while it increases from II to III. This is a clear indication that HRT $=12$ days could be the lowest acceptable HRT for the methanogenic bioreactor in TSAD using OMW as the feed. It should be pointed out that this value is about $1 / 3$ or lower than the HRT used in a one-step AD (30-40 days), and hence, the volume of the vessel decreases as do the capital and operative costs. Figure 6 shows the FF variations along the three tested HRT, which were evaluated at each time interval equal to the HRT for S2. From Fig. 6, it is possible to argue that, after the occurrence of a perturbation, it is necessary to wait for a time that is at least equal about three times HRT for the perturbation to be assimilated, as is possible to see for $\mathrm{S} 2$ for HRT $=11$ days, where the instability is smoothed out in the subsequent 2 HRT.
Fig. 6 Fano factor evaluated for each HRT unit time for the tested HRT I, II, and III

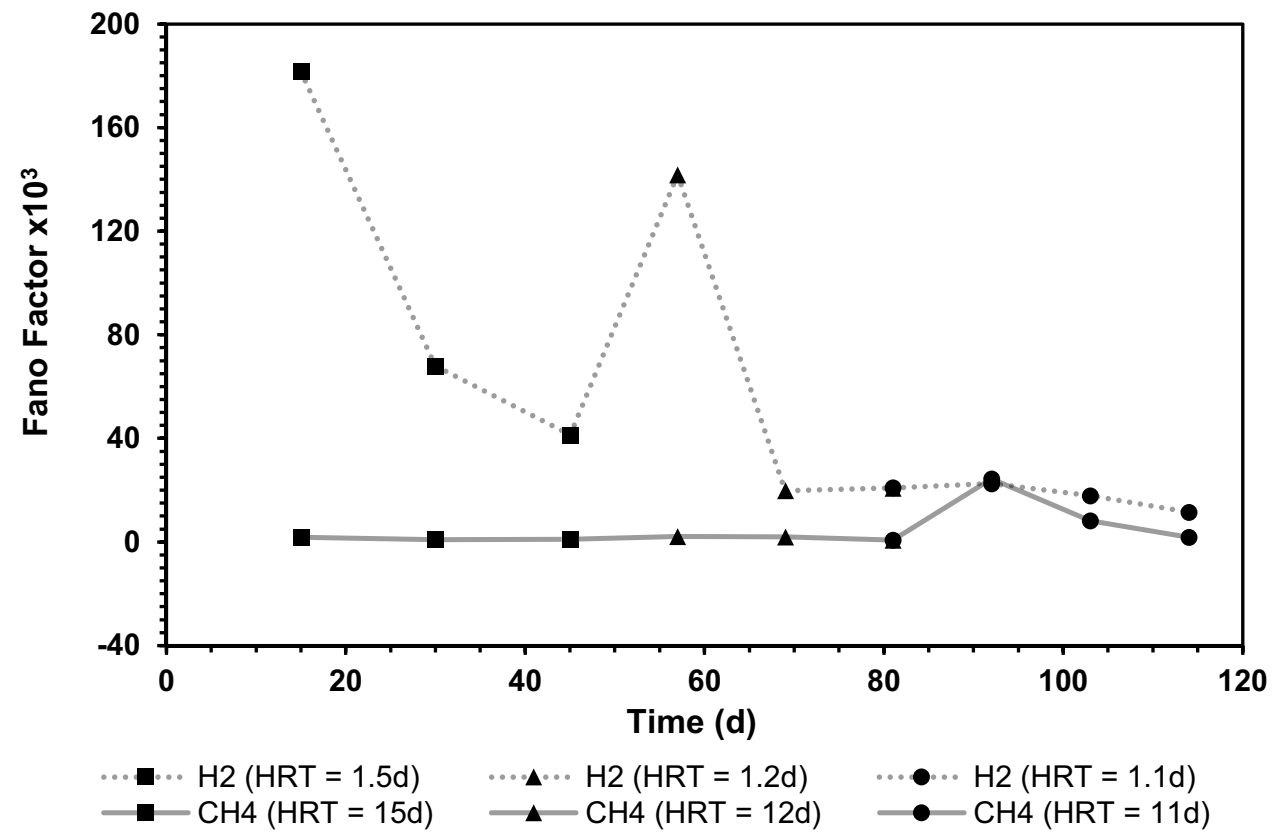




\section{Energetic performance of the TSAD}

As a result of the different biological pathways that lead to hydrogen and methane production at a cellular level, the productivity of $\mathrm{H}_{2}$ in $\mathrm{S} 1$ is higher than that of $\mathrm{CH}_{4}$ in $\mathrm{S} 2$, over the 4:1-5:1 range (see Fig. 5), but considering that $\mathrm{LHV}_{\mathrm{CH}_{4}}$ is more than 3.4 times greater than $\mathrm{LHV}_{\mathrm{H}_{2}}$ (see "Efficiency $(\eta)$ and efficacy $(\zeta)$ evaluations"), and that the volume of S2 is ten times that of $\mathrm{S} 1$, the most important contribution to the overall energy is the methanogenic one. The cumulative energy produced in $\mathrm{S} 1$ and $\mathrm{S} 2$ is shown in Fig. 7; the slopes of the curves provide an estimation of the mean daily rate at which the energy is produced for each operative HRT, while the correlation coefficients $\left(R^{2}\right)$ judges the goodness of the estimations. The daily energy production rate for methane is more than one order of magnitude higher than that of hydrogen. The $\mathrm{CH}_{4}$ slope (MJ/day) increases as HRT decreases, probably due to the higher OLR, while the energy produced daily for $\mathrm{H}_{2}$ is not affected significantly by the operative HRT. Although the $\mathrm{CH}_{4}$ production shows a larger standard deviation $\left(R^{2}\right)$ for condition III, due to the transition II $\rightarrow$ III, this deviation is in agreement with the FF value of $1.72 \times 10^{-2}$ reported in Table 4. Finally, the III condition (HRT $=11$ days) produces more energy per day, but it is more unstable than the longer HRT.

Table 3 offers a compendium of the operative conditions tested along with the performance results obtained for $\mathrm{S} 1$ and $\mathrm{S} 2$ for the TSAD system. The share of $\mathrm{H}_{2}$ that contributes to the overall cumulative produced energy represents only $12.15 \%$ for I, $12.25 \%$ for II, and $7.6 \%$ for III, and it can be estimated from the ratio of the slopes of the hydrogen and methane curves presented in Fig. 7. Luo et al. [27] studied a
TSAD with different HRT relations between $\mathrm{S} 1$ and $\mathrm{S} 2$, that is, of 3:14 and 1:14, and they achieved an energy recovery of $\mathrm{H}_{2}$ accounting for $14 \%$ of the overall energy, an outcome which is in agreement with the results of this work. The daily energy production data, presented in Table 3 , represent the mean values, computed on a daily basis and, therefore, differ marginally from the slopes in Fig. 7. In addition, from Table 3 it is possible to see that TSAD is able to manage higher OLR than one-step-AD, which is of $3-4 \mathrm{~g}_{\mathrm{vS}} /(\mathrm{L}$ day), which is a very important aspect for the full-scale application [28].

To apply the energy performance evaluation procedure highlighted in "Efficiency $(\eta)$ and efficacy $(\zeta)$ evaluations", the experimental measurement of the LHV of OMW was used to determine the energy content of the substrate. In the biogas technology field, different methods have been proposed to evaluate the maximum amount of energy that can be obtained from organic wastes. In the authors' opinion, the use of an LHV value offers a more standard approach than BMP tests, which can be ambiguous as a result of the lack of a generally accepted standard measurement protocol [29] and due to the difficulties associated with the replicability of these tests, which can generate large uncertainties, which, in some cases, are beyond acceptable thresholds. Instead, the experimental evaluation of LHV follows a standard procedure that can be employed for any kind of fuel, of either a biological or chemical nature [30]. In fact, LHV has been related to the degree of reduction of biological systems [31] and different empirical correlations have been proposed to link LHV to the measurement of the chemical oxygen demand (COD) and to the DM or VS for sewage sludges [30]. The experimentally tested $\mathrm{LHV}_{\mathrm{OMW}}$
Fig. 7 Cumulative energy production for the tested HRT

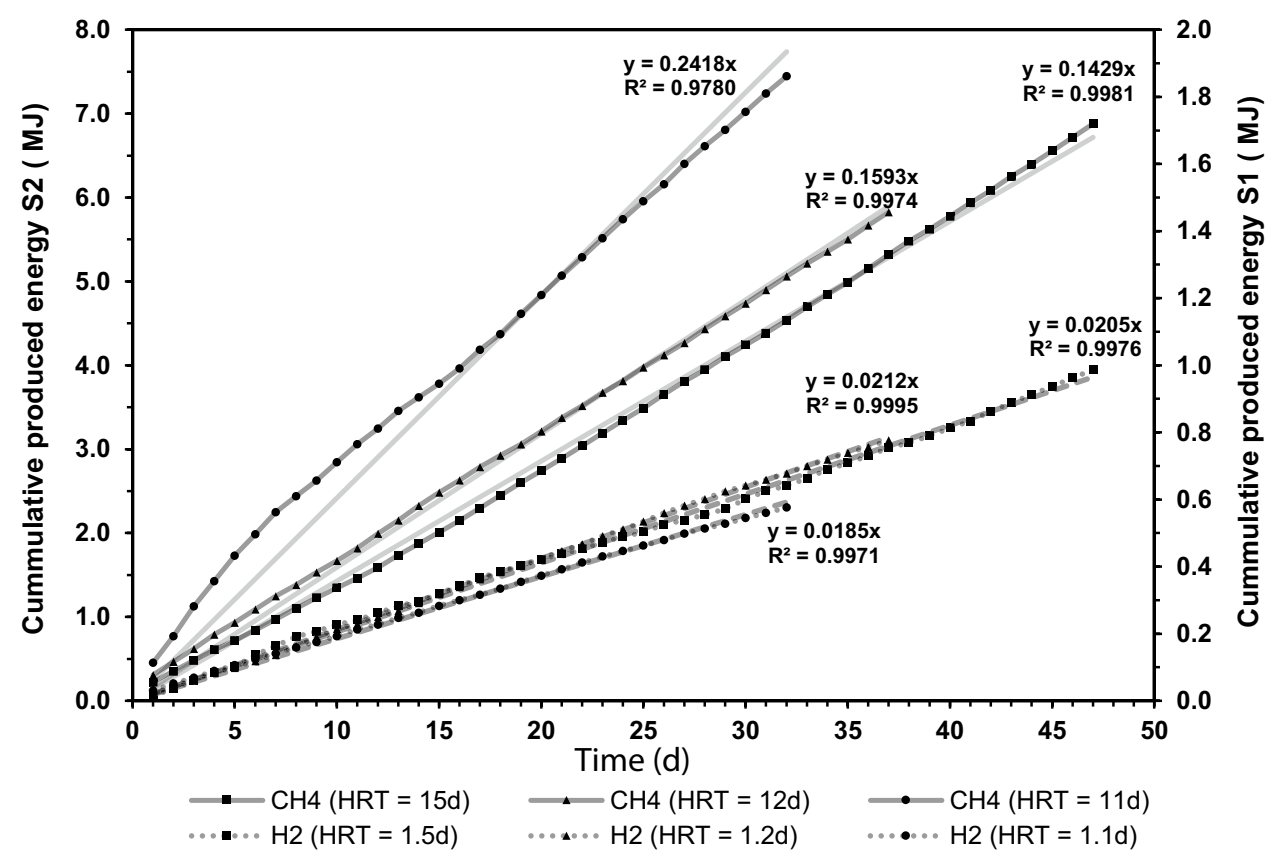


was around $14,538 \mathrm{~kJ} / \mathrm{kg}_{\mathrm{DM}}$, with a relative uncertainty of $\pm 10 \%$, which was due to the fluctuations in the composition of the mixed collected fruit and vegetables, along with seasonal changes. The application of Eq. (3) led to the results of $\eta$ reported in Table 3 for each tested HRT. These results showed that the best energetic performance of the TSAD system was achieved at operative condition III, i.e., for the shortest HRT and the highest OLR for S2. As far as the efficacy $\zeta$ of the TSAD compared to the classic one-step AD is concerned, Table 3 reports the results of the application of Eq. 4, with reference values (Eq. 5) of $\mathrm{Ep}_{\mathrm{AD}}$ of 139.27, 192.67, and 188.55 (kJ/day) for I, II, and III, respectively. From Table 3, it is possible to see that the quantity of energy produced in the TSAD process, even though affected by the different HRT conditions, is about $20 \%$ higher than that of one-step AD. The efficacy indicator quantifies the improvements, albeit only in terms of energetic performance. In fact, the lower bioreactor volume in TSAD, as a consequence of the lower HRT than in one-step-AD, also needs to be considered, as reported above.

Some authors have suggested that TSAD is not suitable for all the substrates. Linder et al. [32] have recently tested TSAD for different feedstocks and concluded that it is more suitable for sugar-rich feeds. However, in their experimental set-up, it is difficult to understand whether a clear difference of HRT between the acidogenic and the methanogenic bioreactor was considered. In the authors' opinion, HRT plays a fundamental role in ensuring the separation of microbiome HPB and HCB in S1, along with process parameters that should be controlled. The present experimental tests were conducted with OMW, which is a very complex feed containing carbohydrates, lignocellulose, and other organic material, and the obtained results confirm that the microbiome in either S1 or S2 adapted well to the used materials as a substrate to assure a stable bioenergy recovery. In addition, the obtained discharge water, used after filtration of the S2 effluent to dilute the OMW feed in $\mathrm{S} 1$, certainly contained $\mathrm{HCB}$ microbiomes, albeit at low concentrations. Considering that no $\mathrm{CH}_{4}$ was detected in the gas output stream from $\mathrm{S} 1$ which means that the adopted strategy, mainly the kinetic selection of HCB and HPB, was effective in the separation of HCB microbiome in S1.

Table 5 shows the results of this study compared with literature data. The study of TSAD literature selected for comparison purposes only considered tests pertaining to different organic substrates, and only in continuous mode. The study by [30] did not consider hydrogen production in the first stage, since no hydrogen was produced in their system under steady-state operation conditions, due to the fact that both bioreactors were operated at the same HRT. It is interesting to note, in Table 5, that TSAD leads to flexibility, in terms of the variation of the organic substrate, that is, OLR and HRT, and that the obtained yields of hydrogen and methane depend on the substrate feed.

Finally, the process parameters for S1 and S2 are summarised in Table 6, where the experimental observations of this work and the choices made to guarantee the long-term stability of the TSAD process towards a scale-up procedure are pointed out. TSAD is a growing technology in the field of bioenergy production, but also for material recovery. Moreover, it is gaining ground as one of the most interesting applications of MCE principles and it can help in the development of innovative processes designs. The separation of microbiomes occurs in continuous TSAD to some extent as a result of the different initial inocula, but the process parameters and stressors (or selective pressure) are also critical

Table 5 Comparison among continuous TSAD systems from literature

\begin{tabular}{|c|c|c|c|c|c|c|c|c|c|c|}
\hline \multirow[t]{2}{*}{ References } & \multirow[t]{2}{*}{ Substrate } & \multicolumn{2}{|c|}{ Yield $\left(\mathrm{NL} / \mathrm{g}_{\mathrm{vS}}\right)$} & \multicolumn{2}{|c|}{$\mathrm{OLR}\left[\mathrm{g}_{\mathrm{VS}} /(\mathrm{L} /\right.$ day $\left.)\right]$} & \multirow{2}{*}{$\begin{array}{l}\text { HRT (day) } \\
\text { S1 }\end{array}$} & \multicolumn{2}{|c|}{ Time $^{\mathrm{a}}$ (day) } & \multicolumn{2}{|c|}{$\begin{array}{l}\text { Temp. } \\
\left({ }^{\circ} \mathrm{C}\right)\end{array}$} \\
\hline & & $\mathrm{S} 1\left(\mathrm{H}_{2}\right)$ & $\mathrm{S} 2\left(\mathrm{CH}_{4}\right)$ & $\mathrm{S} 1\left(\mathrm{H}_{2}\right)$ & $\mathrm{S} 2\left(\mathrm{CH}_{4}\right)$ & & S2 & & $\mathrm{S} 1$ & $\mathrm{~S} 2$ \\
\hline [33] & Food waste & - & 0.48 & - & - & 30 & 30 & 120 & 55 & 55 \\
\hline [34] & Swine manure + OMW & 0.14 & 0.35 & 11.24 & 1.16 & 3 & 22 & 25 & 55 & 55 \\
\hline [35] & Food waste & 0.01 & $0.37-0.42$ & $6.00-15.00$ & $2.00-5.00$ & 4 & 12 & - & 55 & 55 \\
\hline [36] & Food waste & - & $0.31-0.61$ & - & $0.81-4.84$ & $1-5$ & $5-30$ & 30 & 38 & 38 \\
\hline$[37]^{\mathrm{b}}$ & Whey permeate & $0.03-0.16$ & $0.05-0.11$ & $21.32-37.31$ & $4.31-7.97$ & 1 & 3 & 75 & 35 & 35 \\
\hline$[38]^{\mathrm{b}}$ & POME & $0.11-0.13$ & $0.14-0.19$ & $13.33-40.00$ & $4.95-5.07$ & 2 & 15 & 120 & 55 & 31 \\
\hline$[39]^{\mathrm{b}}$ & POME & 0.14 & 0.21 & 50 & 5.16 & 2 & 5 & 120 & 55 & 37 \\
\hline$[40]^{\mathrm{c}}$ & Maize silage & $0.02-0.05$ & $0.11-0.16$ & $4.90-6.30$ & $1.40-1.60$ & 16.9 & 16.9 & 60 & 38 & 38 \\
\hline [41] & Food waste & $0.05-0.16$ & $0.03-0.81$ & 16.3 & $2.2-5.6$ & 5 & $8-30$ & 270 & 55 & 35 \\
\hline This study & OMW & $0.05-0.07$ & $0.12-0.18$ & $19.39-26.84$ & $1.27-1.95$ & $1.1-1.5$ & $11-15$ & 140 & 35 & 35 \\
\hline
\end{tabular}

${ }^{a}$ Overall testing time in days

${ }^{\mathrm{b}}$ Data were converted from COD to VS using the mean composition given for the substrate

${ }^{\mathrm{c}}$ The feed was semi-continuous, but both bioreactors were operated in continuous-mode 
Table 6 Suggested process parameters of the TSAD configuration for S1 and S2

\begin{tabular}{|c|c|c|c|}
\hline Process parameters & S1 & S2 & Comments \\
\hline$T\left({ }^{\circ} \mathrm{C}\right)$ & 35 to 55 & $35-55$ & $\begin{array}{l}\text { Mesophilic and thermophilic operations are possible, even combinations of them; pos- } \\
\text { sible competition among mesophilic and thermophilic microorganisms } \\
\text { Convenience of energy-recovery should be carefully evaluated at thermophilic conditions }\end{array}$ \\
\hline OLR $\left[\mathrm{g}_{\mathrm{VS}} /(\mathrm{L}\right.$ day $\left.)\right]$ & 1 to 40 & $1-5$ & $\begin{array}{l}\text { HPB are less sensitive than HCB to substrate inhibitions, and, therefore, } \mathrm{S} 1 \text { consent } \\
\text { operation at higher OLR } \\
\text { Indirect influence on the bioreactor volume }\end{array}$ \\
\hline HRT (day) & 1 to 3 & $10-20$ & $\begin{array}{l}\text { The choice of HRT should be based on the characteristic of the feed and growth kinetics } \\
\text { of the microbiome for each stage } \\
\text { HRT can be scanned for particular substrates, but operation should maintain fixed HRT } \\
\text { values to promote microbiome stability (HPB in S1 and HPB + HCB in S2) }\end{array}$ \\
\hline Volumetric power $\left(\mathrm{W} / \mathrm{m}^{3}\right)$ & 100 & 50 & $\begin{array}{l}\mathrm{HPB} \text { are more sensitive to product inhibition }\left(\mathrm{H}_{2}\right) \text { and, therefore, higher mixing in } \\
\text { required (degassing) } \\
\text { HCB present a lower shear stress resistance than HPB } \\
\text { In } \mathrm{S} 2 \text {, granule formation (HPB }+\mathrm{HCB} \text { ) is favoured at low mixing intensities }\end{array}$ \\
\hline $\mathrm{pH}$ & 5 to 6 & $7-7.5$ & $\begin{array}{l}\text { Optimal } \mathrm{pH} \text { is different for } \mathrm{S} 1 \text { and } \mathrm{S} 2 \\
\text { Lower HRT in } \mathrm{S} 1 \text { can cause process instabilities due to shifts in } \mathrm{pH} \text { and microbiomes } \\
\text { (VFA acid accumulation and solvents production) }\end{array}$ \\
\hline Red-Ox (mV) & +100 to $(-200)$ & $<-330$ & $\begin{array}{l}\text { HPB can be either anaerobes or facultative aerobes, while HCB and especially methano- } \\
\text { gens are strictly anaerobes }\end{array}$ \\
\hline
\end{tabular}

aspects for the stability and the performance of the system over the long term; therefore, linking biological knowledge with process engineering can offer an opportunity for sustainable solutions based on the emerging field of MCE.

\section{Conclusion}

The assessment of the energetic performance of the TSAD system is a laborious task, due to the considerable number of variables, such as feed variabilities (OMW), which is constituted by complex organic substrates, the inherent complexity of the biological systems of mixed cultures, and bioreactor spatial heterogeneities problems. The selection of the microbial consortia for $\mathrm{S} 1$ and $\mathrm{S} 2$, through an acidic treatment to enrich HPB, and the use of adequate stressors, mainly HRT based on the kinetic selection of the microorganism parameters was effective, as no $\mathrm{CH}_{4}$ was found in the produced gas in the hydrogen reactor. The correct selection of the microbiome for each bioreactor of the TSAD is fundamental to maintain the performance of the system for a long operational time at full scale. The choice to test the TSAD system for at least three cycles for each HRT condition of S2 proved to be useful, since S1 acts as a damping system, by ensuring a stable $\mathrm{CH}_{4}$ production under steadystate conditions. A very low amplitude of oscillations and progressive reduction were in fact observed in the methanogenic bioreactor, as quantified by the Fano factor over time. As far as the stability analysis of the steady-state condition is concerned, HRT = 11 days seems to be more unstable than HRT $=12$ days, and an even higher energy production resulted in the latter condition. In terms of energy recovery, as TSAD produced about $20 \%$ more than one-step AD, while the rationalisation and optimisation of HRT could result in significant reductions of the volume (and costs). As concerns the volume of the $\mathrm{CH}_{4}$ fermenter, which is the largest one, it could be reduced to $1 / 3$ or more the volume of a one-step AD. Finally, the managed OLR could be $4-5$ times that of one-step-AD. The authors believe that the present results are very promising for the full-scale application of TSAD, even though additional experimental tests are still necessary for various substrates.

\section{Compliance with ethical standards}

Conflict of interest None; the authors confirm that there are no known conflicts of interest associated with this publication and that this research has not received any specific grant from funding agencies in the public, commercial, or not-for-profit sectors.

Open Access This article is distributed under the terms of the Creative Commons Attribution 4.0 International License (http://creativeco mmons.org/licenses/by/4.0/), which permits unrestricted use, distribution, and reproduction in any medium, provided you give appropriate credit to the original author(s) and the source, provide a link to the Creative Commons license, and indicate if changes were made.

\section{References}

1. EurObserv'ER: Press Release: Biogas Barometer, Paris (2017) 
2. Ben-Iwo, J., Manovic, V., Longhurst, P.: Biomass resources and biofuels potential for the production of transportation fuels in Nigeria. Renew. Sustain. Energy Rev. 63, 172-192 (2016). https ://doi.org/10.1016/J.RSER.2016.05.050

3. Franke-Whittle, I.H., Walter, A., Ebner, C., Insam, H.: Investigation into the effect of high concentrations of volatile fatty acids in anaerobic digestion on methanogenic communities. Waste Manag. 34, 2080-2089 (2014). https://doi.org/10.1016/j.wasma n.2014.07.020

4. Liu, Y., Whitman, W.B.: Metabolic, phylogenetic, and ecological diversity of the methanogenic archaea. Ann. N. Y. Acad. Sci. 1125, 171-189 (2008). https://doi.org/10.1196/annals.1419.019

5. Bagi, Z., Ács, N., Bálint, B., Horváth, L., Dobó, K., Perei, K.R., Rákhely, G., Kovács, K.L.: Biotechnological intensification of biogas production. Appl. Microbiol. Biotechnol. 76, 473-482 (2007). https://doi.org/10.1007/s00253-007-1009-6

6. Gomez Camacho, C.E., Ruggeri, B.: Syntrophic microorganisms interactions in anaerobic digestion (AD): a critical review in the light of increase energy production. Chem. Eng. Trans. (2018). https://doi.org/10.3303/cet1864066

7. Bader, J., Mast-Gerlach, E., Popović, M.K., Bajpai, R., Stahl, U.: Relevance of microbial coculture fermentations in biotechnology. J. Appl. Microbiol. 109, 371-387 (2010). https://doi.org/10.111 1/j.1365-2672.2009.04659.x

8. Koch, C., Müller, S., Harms, H., Harnisch, F.: Microbiomes in bioenergy production: from analysis to management. Curr. Opin. Biotechnol. 27, 65-72 (2014). https://doi.org/10.1016/j.copbi o.2013.11.006

9. Oliveira, C.S.S., Silva, C.E., Carvalho, G., Reis, M.A.: Strategies for efficiently selecting PHA producing mixed microbial cultures using complex feedstocks: feast and famine regime and uncoupled carbon and nitrogen availabilities. N. Biotechnol. 37, 69-79 (2017). https://doi.org/10.1016/J.NBT.2016.10.008

10. Ruggeri, B., Tommasi, T., Sanfilippo, S.: $\mathrm{BioH}_{2}$ and $\mathrm{BioCH}_{4}$ through anaerobic digestion: from research to fullscale applications. Springer, London (2015). https://doi. org/10.1007/978-1-4471-6431-9

11. Łukajtis, R., Hołowacz, I., Kucharska, K., Glinka, M., Rybarczyk, P., Przyjazny, A., Kamiński, M.: Hydrogen production from biomass using dark fermentation. Renew. Sustain. Energy Rev. 91, 665-694 (2018). https://doi.org/10.1016/J.RSER.2018.04.043

12. Siddiqui, Z., Horan, N.J., Sahito, A.R., Abdulkadir, J., Memon, S.A.: Optimising the production of energy from coblended food waste and biosolids using batch reactor studies. Water Environ. J. 28, 483-489 (2014). https://doi.org/10.1111/wej.12060

13. Luongo Malave', A.C., Bernardi, M., Fino, D., Ruggeri, B.: Multistep anaerobic digestion (MAD) as a tool to increase energy production via $\mathrm{H}_{2}+\mathrm{CH}_{4}$. Int. J. Hydrog. Energy. 40, 5050-5061 (2015). https://doi.org/10.1016/j.ijhydene.2015.02.068

14. Malavè, A.C.L., Fino, D., Gómez Camacho, C.E., Ruggeri, B.: Experimental tests on commercial sweet product residue (SPR) as a suitable feed for anaerobic bioenergy $\left(\mathrm{H}_{2}+\mathrm{CH}_{4}\right)$ production. Waste Manag 71, 626-635 (2018). https://doi.org/10.1016/j. wasman.2017.06.011

15. Winkler, M.-K.H., Boets, P., Hahne, B., Goethals, P., Volcke, E.I.P.: Effect of the dilution rate on microbial competition: r-strategist can win over k-strategist at low substrate concentration. PLoS One 12, 1-12 (2017). https://doi.org/10.1371/journ al.pone. 0172785

16. Gómez Camacho, C.E., Romano, F.I., Ruggeri, B.: Macro approach analysis of dark biohydrogen production in the presence of zero valent powered $\mathrm{Fe}^{\circ}$. Energy 159, 525-533 (2018). https://doi.org/10.1016/j.energy.2018.06.171

17. Ruggeri, B., Luongo Malave, A.C., Bernardi, M., Fino, D.: Energy efficacy used to score organic refuse pretreatment processes for hydrogen anaerobic production. Waste Manag. 33, 2225-2233 (2013). https://doi.org/10.1016/j.wasman.2013.06.024

18. Angelonidi, E., Smith, S.R.: A comparison of wet and dry anaerobic digestion processes for the treatment of municipal solid waste and food waste. Water Environ. J. 29, 549-557 (2015). https://doi. org/10.1111/wej.12130

19. Ruggeri, B., Tommasi, T., Sassi, G.: Experimental kinetics and dynamics of hydrogen production on glucose by hydrogen forming bacteria (HFB) culture. Int. J. Hydrog. Energy 34, 753-763 (2009). https://doi.org/10.1016/j.ijhydene.2008.10.076

20. American Public Health Association, American Water Works Association, Water Environment Federation, Standard Methods for the Examination of Water and Wastewater, Standard Methods for the Examination of Water and Wastewater, APHA (1999)

21. Veldkamp, H.: Mixed culture studies with the chemostat. J. Appl. Chem. Biotechnol. 22, 105-123 (1972). https://doi.org/10.1002/ jctb.2720220113

22. Ferguson, R.M.W., Coulon, F., Villa, R.: Organic loading rate: a promising microbial management tool in anaerobic digestion. Water Res. 100, 348-356 (2016). https://doi.org/10.1016/j.watre s.2016.05.009

23. Fano, U.: Ionization yield of radiations. II. The fluctuations of the number of ions. Phys. Rev. 72, 26-29 (1947). https://doi. org/10.1103/physrev.72.26

24. Cox, D.R., Isham, V.: Point Processes. Taylor \& Francis, London (1980)

25. Thattai, M., van Oudenaarden, A.: Intrinsic noise in gene regulatory networks. Proc. Natl. Acad. Sci. 98, 8614-8619 (2001). https ://doi.org/10.1073/pnas.151588598

26. Barato, A.C., Seifert, U.: Universal bound on the Fano factor in enzyme kinetics. J. Phys. Chem. B. 119, 6555-6561 (2015). https ://doi.org/10.1021/acs.jpcb.5b01918

27. Luo, G., Xie, L., Zhou, Q., Angelidaki, I.: Enhancement of bioenergy production from organic wastes by two-stage anaerobic hydrogen and methane production process. Bioresour. Technol. 102, 8700-8706 (2011). https://doi.org/10.1016/j.biort ech.2011.02.012

28. Deublein, D., Steinhauser, A.: Biogas from waste and renewable resources: an introduction. Wiley, Weinheim (2011). https://books .google.it/books?id=CJiMmmxu2tcC. Accessed 1 Feb 2019

29. Esposito, G., Frunzo, L., Liotta, F., Panico, A., Pirozzi, F.: Biomethane potential tests to measure the biogas production from the digestion and co-digestion of complex organic substrates. Open Environ. Eng. J. 5, 1-8 (2012). https://doi.org/10.2174/18748 29501205010001

30. Schaum, C., Lensch, D., Cornel, P.: Evaluation of the energetic potential of sewage sludge by characterization of its organic composition. Water Sci. Technol. 73, 3072-3079 (2016). https://doi. org/10.2166/wst.2016.188

31. Gary, C., Frossard, J., Chenevard, D.: Heat of combustion, degree of reduction and carbon content: 3 interrelated methods of estimating the construction cost of plant tissues. Agronomie. 15, 59-69 (1995). https://doi.org/10.1051/agro:19950107

32. Lindner, J., Zielonka, S., Oechsner, H., Lemmer, A.: Is the continuous two-stage anaerobic digestion process well suited for all substrates? Bioresour. Technol. 200, 470-476 (2016). https://doi. org/10.1016/J.BIORTECH.2015.10.052

33. Xiao, B., Qin, Y., Wu, J., Chen, H., Yu, P., Liu, J., Li, Y.-Y.: Comparison of single-stage and two-stage thermophilic anaerobic digestion of food waste: performance, energy balance and reaction process. Energy Convers. Manag. 156, 215-223 (2018). https:// doi.org/10.1016/J.ENCONMAN.2017.10.092

34. Schievano, A., Tenca, A., Scaglia, B., Merlino, G., Rizzi, A., Daffonchio, D., Adani, F.: Two-stage vs single-stage thermophilic anaerobic digestion: comparison of energy production and 
biodegradation efficiencies. Environ. Sci. Technol. 46, 8502-8510 (2012). https://doi.org/10.1021/es301376n

35. Voelklein, M.A., Jacob, A., O' Shea, R., Murphy, J.D.: Assessment of increasing loading rate on two-stage digestion of food waste. Bioresour. Technol. 202, 172-180 (2016). https://doi. org/10.1016/j.biortech.2015.12.001

36. Wang, G.H., Wang, L., Tan, X.J., Wang, Y.X., Wang, F.: Twophase mesophilic anaerobic co-digestion of food waste and sewage sludge: effect of hydraulic retention time. Adv. Mater. Res. 852, 789-796 (2014). https://doi.org/10.4028/www.scientific.net/ AMR.852.789

37. Kisielewska, M., Wysocka, I., Rynkiewicz, M.R.: Continuous biohydrogen and biomethane production from whey permeate in a two-stage fermentation process. Environ. Prog. Sustain. Energy. (2013). https://doi.org/10.1002/ep.11890

38. Thong, S.O., Suksong, W., Promnuan, K., Thipmunee, M., Mamimin, C., Prasertsan, P.: Two-stage thermophilic fermentation and mesophilic methanogenic process for biohythane production from palm oil mill effluent with methanogenic effluent recirculation for $\mathrm{pH}$ control. Int. J. Hydrog. Energy. 41, 21702-21712 (2015). https://doi.org/10.1016/j.ijhydene.2016.07.095
39. Krishnan, S., Singh, L., Sakinah, M., Thakur, S., Nasrul, M., Otieno, A., Wahid, Z.A.: Process enhancement of hydrogen and methane production from palm oil mill effluent using two-stage thermophilic and mesophilic fermentation. Int. J. Hydrog. Energy 41, 12888-12898 (2016). https://doi.org/10.1002/ep.12537

40. Benito Martin, P.C., Schlienz, M., Greger, M.: Production of bio-hydrogen and methane during semi-continuous digestion of maize silage in a two-stage system. Int. J. Hydrog. Energy. 42, 5768-5779 (2017). https://doi.org/10.1016/j.ijhydene.2017.01.020

41. Algapani, D.E., Qiao, W., di Pumpo, F., Bianchi, D., Wandera, S.M., Adani, F., Dong, R.: Long-term bio- $\mathrm{H}_{2}$ and bio- $\mathrm{CH}_{4}$ production from food waste in a continuous two-stage system: energy efficiency and conversion pathways. Bioresour. Technol. 248, 204-213 (2018). https://doi.org/10.1016/j.biortech.2017.05.164

Publisher's Note Springer Nature remains neutral with regard to jurisdictional claims in published maps and institutional affiliations. 